\title{
Answer to the Letter to the Editor of C. Brembilla et al. concerning "Dynamic cervical myelopathy in young adults" by Hattou L, Morandi X, Le Reste PJ, et al: Eur Spine J 2014, 23:1515-22
}

\author{
Pierre-Louis Hénaux
}

Received: 4 February 2015/Revised: 4 February 2015/Accepted: 4 February 2015/Published online: 7 March 2015

(c) Springer-Verlag Berlin Heidelberg 2015

\section{Dear Editor,}

We thank you for your interest in our article entitled "Dynamic cervical myelopathy in young adults" and we found that the comments were helpful for the improvement of our paper. We read with great interest these comments but we think nevertheless that chronic joint instability explains dynamic medullary compression in patients of our series for these three reasons:

1. Patients with dynamic cervical myelopathy had a clinical instability. All of them had a cervical pain and consecutive loss of mention stiffness. Three of them had in addition Lhermitte's sign.

2. They had also a radiological instability because anterior impingement with medullary compression was always observed in extension in this population of patients. In a physiologic condition, cervical disc budge in flexion and not in extension [1].
3. Last, during the surgery, we observed in all cases a degenerative disc with an excessive motion between the two adjacent vertebrae corroborating chronic joint instability.

Conflict of interest None.

\section{Reference}

1. Muhle C, Wiskirchen J, Weinert D, Falliner A, Wesner F, Brinkmann G, Heller M (1998) Biomechanical aspects of the subarachnoid space and cervical cord in healthy individuals examined with kinematic magnetic resonance imaging. Spine (Phila Pa 1976) 23(5):556-567

\section{P.-L. Hénaux $(\bowtie)$}

Department of Neurosurgery, Rennes University Hospital,

Pontchaillou University Hospital, CHU Pontchaillou, 2 rue Henri

Le Guilloux, 35033, Rennes Cedex 9, France

e-mail: pierre-louis.henaux@ chu-rennes.fr 